\title{
A unified approach to evaluate green hospitals' certification criteria
}

\author{
A.B. Candaş, O.B. Tokdemir* \\ Middle East Technical University, Faculty of Engineering, Department of Civil Engineering, Ankara, \\ Turkey
}

\begin{abstract}
There are many Green Hospitals certification criteria in the industry, depending on the institute that issues the certification. Designers, builders, owners aim to achieve these criteria requirements in their studies but not always consider the end user's perspective. The aim of this article is to determine the most valuable LEED certification criteria, that contributes towards the success of the project after it is built, from the end user's perspective in hospitals with LEED certification in Turkey. The authors hypothesized that easiness and comfort values related to LEED certification criteria are the general values that end-users are looking for in their working environment. In order to determine the most valuable criteria, authors have selected a focus group of people who have working experience in both LEED and non-LEED certified hospitals. First, the Delphi technique is utilized to generate a list of advantages for working at a LEED-certified hospital, and then a shorter list is generated by comparison of the abovementioned list with LEED certification criteria. Finally, Analytic Hierarchy Process (AHP) is used to find out the most valuable LEED certification criteria. The hypothesis has been confirmed with AHP results.
\end{abstract}

\section{Keywords}

Green hospital; LEED; Analytic hierarchy process; Certification criteria; Delphi technique

Received: 03 September 2019; Accepted: 24 September 2019

ISSN: 2630-5771 (online) C 2019 Golden Light Publishing All rights reserved.

\section{Introduction}

The demand for Green Hospitals is expeditiously becoming the most significant trend in the healthcare construction sector. Constructing a Green Hospital is achieved mainly by the following criteria; its maximization of economic benefits, addressing the quality, reduction in waste, and minimization of adverse environmental impacts. In other words, Green Hospitals provide decreased operation costs, energy, and water usage and better clinical results [1].

Leadership in Energy and Environmental Design (LEED), which was developed in 1993 by the U.S. Green Building Council (USGBC), is a voluntary environmental certification system aiming at the development of high performance and sustainable buildings. LEED, with 96,275 both certified and registered projects in more than 167 countries, is the most widespread and recognized green building certification and rating system of the world. Turkey is ranked as the sixth country outside of the US in terms of cumulative LEED-certified gross square meters in 2018 [2]. In July 2019, USGBC also announced that Turkey had 357 certified and 523 registered LEED projects with a total of 39.1 million gross square meters. As of July 2019, USGBC [2] demonstrated the current status

* Corresponding author

Email: tokdemir@metu.edu.tr 
of green healthcare facilities in Turkey, as shown in Fig. 1.

LEED certification for building design and construction is known as LEED BD+C. This category of LEED certification further subcategorized to use of the building, and for this article, only healthcare facilities were studied. In other words; LEED BD+C: Healthcare was specifically activated for healthcare facilities and other hospitals that operate on 24/7 schedules and provide inpatient medical treatment. Healthcare projects can earn credits from several categories which are sustainable sites (SS), water efficiency (WE), energy and atmosphere (EA), materials and resources (MR), indoor environmental quality (IEQ), innovation and design (ID) and regional priority (RP) credits. The scorecards of three LEED gold-certified healthcare facilities in Turkey are detailed in terms of abovementioned category credits in Table 1.

In this article, authors try to find out the most valuable LEED certification criteria, that are presented in Table 1, from the end user's perspective. Thus, the initial approach utilized in this paper is the Delphi technique. Delphi technique is implemented with participants from the healthcare sector. With the help of this technique and the questionnaire results obtained from the endusers, questionnaire participants, the most valuable certification criteria can be found. Yet, these results will not present the relative importance of what has been found. Thus; in order to overcome this inadequacy, the authors utilized the AHP technique.

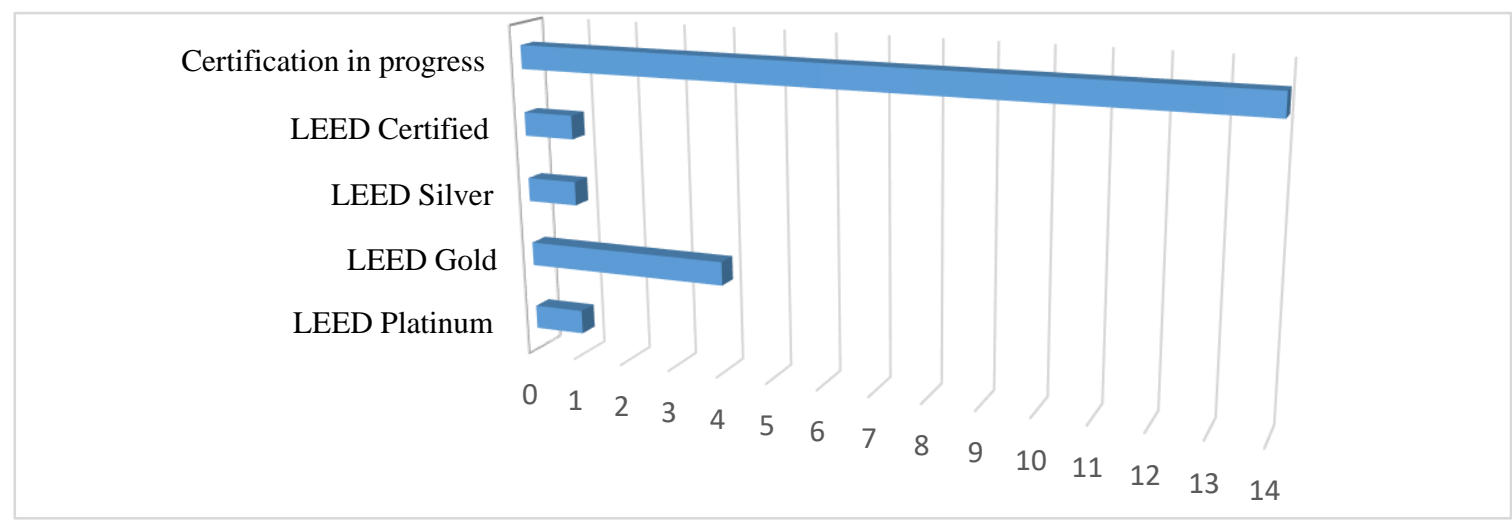

Fig. 1. Current status of green healthcare facilities in Turkey [2]

Table 1. Gold-certified LEED scorecards of green healthcare facilities in Turkey [2]

\begin{tabular}{lccc}
\hline LEED Scorecard & $\begin{array}{c}\text { Yozgat City } \\
\text { Hospital }\end{array}$ & $\begin{array}{c}\text { Adana City } \\
\text { Hospital }\end{array}$ & $\begin{array}{c}\text { Elazig City } \\
\text { Hospital }\end{array}$ \\
\hline Sustainable Sites & 12 of 18 & 10 of 18 & 11 of 18 \\
Water Efficiency & 5 of 9 & 7 of 9 & 8 of 9 \\
Energy \& Atmosphere & 15 of 39 & 23 of 39 & 23 of 39 \\
Material \& Resources & 8 of 16 & 8 of 16 & 4 of 16 \\
Indoor Environmental Quality & 11 of 26 & 8 of 26 & 10 of 26 \\
Innovation & 6 of 6 & 3 of 6 & 4 of 6 \\
Regional Priority Credits & 3 of 4 & 3 of 4 & 3 of 4 \\
\hline LEED Scorecard & $60 / 110$ & $62 / 110$ & $63 / 110$ \\
LEED Certification & GOLD & GOLD & GOLD \\
\hline
\end{tabular}




\section{Literature review}

There are many building sustainability rating systems available today to evaluate the performance of the buildings. The well-known rating systems specifically developed for healthcare facilities are as following; Leadership in Energy and Environmental Design (LEED) developed in the United States, Building Research Establishment's Environmental Assessment Method (BREEAM) developed in the United Kingdom, and Green Star developed in Australia. Buffoli et al. [3] evaluated that LEED, BREEAM, and ITACA (Istituto per l'Innovazione e la Trasparenza degli Appalti e la Compatibilità Ambientale, a rating system developed in Italy) rating systems focus on the hospital structure, the presence of technical, design and system aspects, environmental and landscape sustainability. However, it lacks the depth of economic and social aspects affecting the system of healthcare facilities and other aspects, including users' participation and involvement, managerial issues, and health outcomes.

Wittmann [4] stated that sustainable healthcare facility design increases the patient outcomes, improves the safety of both patient and hospital staff, enhances the satisfaction of both patient and hospital staff, develops better community image and loyalty, improves cost savings and increases productivity.

Furthermore, questionnaire results of designers, contractors, owner or providers from Berkeley (CA), New Haven (CT), Chicago (IL) and Orlando (FL) regional conferences on the delivery of healthcare facilities held by Design-Build Institute of America, Phelps et al. [5] indicated that;

- Reduced use of water and energy due to efficient design (34\%), increased indoor air quality (25\%), improved use of daylight (19\%), reduced use of materials with high content of volatile organic compounds (13\%), reduced use of toxic cleaning products and pesticides or herbicides (4\%), and reduced worker injuries and workdays lost $(5 \%)$ are the most valuable benefits of the green healthcare facilities.
- Complexity of facilities (18\%), higher design and construction expenses (35\%), codes and regulations governing the design and operation (10\%), project delivery and contracting practices (14\%), ignorance based on the alternative technologies and material (20\%) and other issues (3\%) are the major obstacles for the delivery of the green healthcare facilities.

- Reduced energy cost (30\%), increased rate of patient recovery $(31 \%)$, reduced average patient stay $(7 \%)$, decreased infection rate $(23 \%)$, minimization of worker injuries and days lost (7\%) and other issues (2\%) are the primary roles of the green healthcare facilities.

There are several studies about elements affecting the satisfaction and comfort of staff members working at healthcare facilities in the literature. Xuan [6] evaluated the performance of LEED-certified healthcare facilities by surveying 164 staff members from one LEED-certified healthcare facility and one non-LEED-certified healthcare facility and surveying 146 staff members from three LEED gold-certified healthcare facilities and 3 LEED Silver-certified healthcare facilities.

- According to the survey results of 51 staff members from LEED-certified healthcare facility and 113 staff members from non-LEEDcertified healthcare facility, all six variables in LEED-certified healthcare facility including building design, ability to meet occupants' needs, space use efficiency, image presented to visitors, personal safety in and around building and cleanliness showed more significant differences in comparison with those in nonLEED-certified healthcare facility.

- According to the survey results of 76 staff members from LEED Silver-certified healthcare facilities and 70 staff members from LEED gold-certified healthcare facility, the staff members in LEED gold-certified healthcare facilities gave the buildings significantly higher ratings in terms of performance variables than those in LEED Silver-certified healthcare facilities.

Kim et al. [7] examined the significant factors influencing healthcare staff members' comfort and 
satisfaction through comparing the perceptions of the healthcare staff from two LEED-certified hospitals with one non-LEED certified hospital both located in Michigan, United States. Based on the overall results from an empirical study targeting three hospitals;

- Healthcare staff members working in LEEDcertified hospitals displayed higher satisfaction scores in all seven items which are mainly happy to work, like the job, well-organized department, adequate safety and health standards, adequate personal space, a balance between work and personal life and excellent to work,

- Lighting, ventilation, hospital layout, and wayfinding affect the occupants' satisfaction with their healthcare environments in both LEED-certified and non-LEED-certified hospitals,

- The perception toward each comfort categories in LEED-certified hospitals influenced occupants' satisfaction toward their workplace significantly,

- The other comfort categories such as indoor natural settings, materials, and colors, and humidity also demonstrated an essential contribution toward overall satisfaction,

- All mean values for each comfort categories including temperature, humidity, noise, ventilation, lighting, layout, wayfinding, materials and colors, indoor natural settings and outdoor range for LEED-certified hospitals were higher than neutral while most of the mean values (excluding lighting and indoor natural settings) for non-LEED certified hospitals were equal to or less than neutral.

Additionally, Huang [8] demonstrated the significant difference between two LEED-certified healthcare facilities and one non-LEED certified healthcare facility in Michigan, United States by conducting a quantitative study using surveys with healthcare staff including doctors and nurses. From the examination of ten comfort categories;

- Seven of the ten comfort categories which are indoor natural settings, lighting, materials and colors, ventilation, humidity, hospital layout, and wayfinding were found to correlate the satisfaction and comfort of healthcare staff,

- Three of the ten comfort categories which are the outdoor lounge, noise, and temperature were found to be irrelevant to the satisfaction level towards their working environments while they perform better in LEED-certified healthcare facilities compared to non-LEED-certified healthcare facility in the study.

Moreover, Harris [9] utilized a multi-method research design and quantitative analysis of data sets from one LEED platinum-certified healthcare facility, two non-LEED-certified new healthcare facilities and three non-LEED-certified existing healthcare facilities and included employee survey responses and human resource employee data provided by the hospital system in order to link the hospital environments to the quality of care and the associated cost of care by the examination of healthcare employee engagement, turnover, illness and injury. Based on the results from the survey;

- Perceptions of the built environment affected the employee engagement and health and wellbeing up to $14 \%$,

- Turnover and injury reductions were significant and resulted in substantial cost differences; a cost reduction of $\$ 2.17 \mathrm{M}$ based on the facility replaced, and a total annual cost reduction in operational costs of $\$ 2.24 \mathrm{M}$ when compared to 2 non-LEED-certified new healthcare facilities. From the patients' point of view, Sadatsafavi et al. [10] compared the performance of nineteen green healthcare facilities with the average performance of traditional hospitals by the utilization of data from the public Hospital Consumer Assessment of Health Plans Survey (HCAHPS). The findings demonstrated that the patients in green healthcare facilities reported a higher overall satisfaction rating in comparison with the traditional ones and recommended to their friends and family. While the relationship between indoor environmental quality credits and HCAHPS scores are not clear, patients in green healthcare facilities reported slightly higher satisfaction with quietness and cleanliness of patient areas. 
Ulusoy [11] evaluated to verify that LEEDcertified healthcare facilities minimize waste production and energy consumption and enhance patient satisfaction. According to the results of patient survey, Hospital Consumer Assessment of Healthcare Providers and Systems (HCAHPS), conducted in 54 LEED-certified healthcare facilities and 23 non-LEED-certified healthcare facilities in the United States based on t-tests,

- Nurses working in LEED-certified healthcare facilities mostly demonstrated better communication with the patients than the ones working in non-LEED-certified healthcare facilities with a significant difference,

- Doctors working in non-LEED certified healthcare facilities mostly demonstrated better communication with the patients than the ones working in LEED-certified healthcare facilities with a negligible difference,

- Patients treated in non-LEED-certified healthcare facilities received quicker help than the ones treated in LEED-certified healthcare facilities with a negligible difference,

- Pain control in LEED-certified healthcare facilities was better than that in non-LEEDcertified healthcare facilities with a negligible difference,

- Medicines usually are not introduced to the patients by hospital staff in both LEED-certified and non-LEED-certified healthcare facilities,

- Non-LEED-certified healthcare facilities are cleaner than LEED-certified healthcare facilities with a negligible difference,

- Non-LEED-certified healthcare facilities made the patients' room quieter than LEED-certified healthcare facilities with a negligible difference,

- Patients rated and recommended the LEEDcertified healthcare facilities higher than nonLEED-certified healthcare facilities with a significant difference.

As explained in all the above literature surveys, the perspective of end-users who work at a green hospital is related to green building certification criteria. Although the perspective may somehow differ for the profession of the evaluator, it can be concluded that there are varying differences between a green hospital and a not green hospital in terms of advantages. This article studies those differences with respect to its relevance with green building certification criteria with a final prioritization evaluation.

\section{Research methodology}

\subsection{Methodology}

In this paper, the Delphi technique is determined as the first research tool. Delphi technique is a group interview method where experts of a subject provide their responses to a questionnaire; then responses are circulated among these experts, then further rounds of responses are collected from these experts for the same questionnaire with the aim of reaching consensus among experts in relation to their responses. In this article, it is aimed to limit the scope of research to determine the most valuable LEED certification criteria by obtaining consensus in the differences of opinion through the Delphi technique. Although this interview technique may take a longer time to reach consensus among experts, yet it allowed authors to receive answers from experts who are geographically separated. In order to apply this technique, a questionnaire was provided to fifteen personnel (end users) working at a LEED-certified hospital. All these hospitals had been in operation for at least a year when abovementioned Delphi questionnaire was applied. Also, this fifteen personnel are randomly selected from varying fields of profession in a hospital, and they also have previous experience at a non-LEED certified hospital. The profession of personnel and number of experts who joined this study are shown in Table 2 below.

Sahin [12] stated that the questionnaire should be undertaken with at least a group of seven people. In the first round of the questionnaire, an openended question was asked to experts in order to avoid directing any expert. The question was, "What do you think are advantages of working at a LEED-certified hospital in comparison to the nonLEED-certified hospital?". 
Table 2. Profession and number of experts

\begin{tabular}{lccc}
\hline Number of Experts & $\begin{array}{c}\text { Yozgat City } \\
\text { Hospital }\end{array}$ & $\begin{array}{c}\text { Adana City } \\
\text { Hospital }\end{array}$ & $\begin{array}{c}\text { Elazig City } \\
\text { Hospital }\end{array}$ \\
\hline Doctors & 1 & 1 & 1 \\
Other Medical Staff & 1 & 1 & 1 \\
Technical Staff (Facility Management) & 1 & 3 & 2 \\
Administration & 1 & 1 & 1 \\
\hline Total & 4 & 6 & 5 \\
\hline
\end{tabular}

Then the second round of Delphi technique was undertaken, and this time, all previous responses were provided to all participants, and they were requested to revisit their previous answers to check if they would like to revise their previous answers. As Sahin [12] stated, in the second round of the questionnaire, the participants were asked to evaluate the answers with the following Likertscaling ' I disagree $=1$, I agree $=7$ '.

The analysis of the answers to the second round of the questionnaire was carried out, and the first and third quartiles, median, and width values of answers were determined. As Sahin [12] points out, the low width value between first and third quartiles suggests that there is a consensus among the participants. On the other hand, the third Delphi questionnaire was prepared on the benefit seen in taking a further step in the consensus and the first and third quartiles, median, and width values were sent to the participants clearly, and the participants were asked to indicate if there are any changes in their opinions. In all applications (rounds) of the Delphi technique, confidentiality was a key element.

Then, a shorter list was obtained from the results of the third questionnaire. This list was created by the answers which are directly related to LEED categories and with median values above 6 .

Prioritization of the list of answers obtained as a result of the Delphi technique would provide benefit owners, designers, engineers, etc. in many ways for their role in project's application for the LEED certification. Thus, in order to prioritize these advantages analytical hierarchy process, which is a multi-criteria decision evaluation methodology, the tool was utilized. Although this tool is used to assess the subjective evaluation of the experts involved, yet the answers of the experts are evaluated for their consistency. Additionally in order to prioritize multi-criteria available, this tool has an applicability advantage of pair-wise comparisons.

Thus, multi-criteria decision evaluation is done by pairwise comparison of the list items obtained as a result of the Delphi technique. In this pairwise comparison, questionnaire participants were asked to scale their preferences from 1 to 9 for each list items. Depending on which item the participant favors, then s/he was asked to rate that item a number between 1 to 9 . This process shall be completed for all pairwise comparison. These comparison scaling will create a matrix where the diagonal values are all equal to 1 , and where we have the upper triangular matrix. In this technique, the lower triangular matrix is obtained by the reciprocals of the upper triangular matrix values. In other words; if aij is the element of row $i$ column $j$ of the matrix, then the lower diagonal is filled using this formula:

$a_{\mathrm{ji}}=\frac{1}{a_{\mathrm{ij}}}$

Then the priority vector, namely eigenvector, and principal eigenvalue, namely $\lambda$, of result matrix are calculated. The results will provide us with the preferences of the participant on the percentage base. The total of the percentage base preferences of a participant will be equal to 1. This AHP technique requires a second check to see if the participant has provided answers in a consistent way, i.e. authors have checked the consistency of 
subjective judgment of the participants. Saaty [13] gave a measure of consistency, namely Consistency Index ("Cl") find by the following formula:

$C I=\frac{\lambda \max -n}{n-1}$

where $\lambda$ is the principal eigenvalue and $n$ is the number of items that are compared. Saaty also proposed to use this index by comparing it with Random Consistency Index ("RI") with the values presented in Table 3.

The comparison is done by the following formula, where Consistency Ratio ("CR") is:

$C R=\frac{C I}{R I}$

If Consistency Ratio is smaller or equal to $10 \%$, the inconsistency is acceptable.

\subsection{Methodology results}

Table 4 below presents a total of 33 advantages stated by the participants in all rounds of the questionnaire, in which all participants provided feedback. Table 4 also presents the statistical values for the advantages, namely first (Q1) and third (Q3) quartiles, median (MD) value and width $(\mathrm{W})$ value achieved at the end of the third round of Delphi technique. Fig. 2 represents this list of advantages in terms of its median values. As a result, there are seven advantages which have median values equal or above six, 20 advantages which have median values between six and equal or above four, and six advantages which have median values below four.

Out of 33 advantages listed in Table 4, there are 9 of them directly related to these LEED categories (sustainable sites (SS), water efficiency (WE), energy and atmosphere (EA), materials and resources (MR), indoor environmental quality (IEQ), innovation and design (ID) and regional priority (RP)). Table 5 presents this sub list.

Table 3. Random consistency index

\begin{tabular}{lcccccccccc}
\hline $\mathrm{n}$ & 1 & 2 & 3 & 4 & 5 & 6 & 7 & 8 & 9 & 10 \\
\hline $\mathrm{RI}$ & 0 & 0 & 0.58 & 0.9 & 1.12 & 1.24 & 1.32 & 1.41 & 1.45 & 1.49 \\
\hline
\end{tabular}

Table 4. The third round of the Delphi questionnaire results

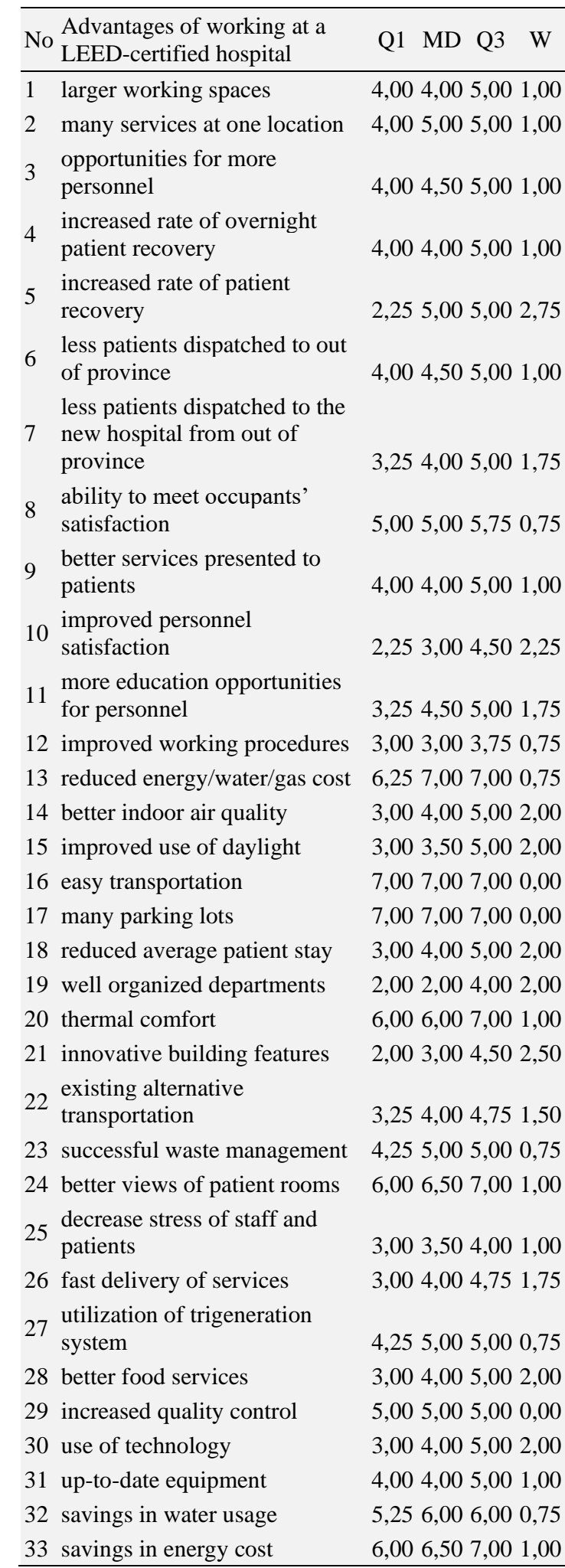




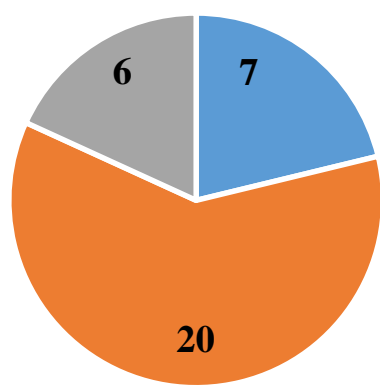

- MEDIAN $>=6$ - $6>$ MEDIAN $>=4-4>$ MEDIAN

Fig. 2. Number of advantages in terms of its median

Table 5. Advantages that are directly related to a LEED category

\begin{tabular}{|c|c|c|}
\hline No & LEED category & $\begin{array}{l}\text { Advantages of working at a } \\
\text { LEED-certified hospital }\end{array}$ \\
\hline 13 & EA & $\begin{array}{l}\text { reduced energy/water/gas } \\
\text { cost }\end{array}$ \\
\hline 16 & SS & easy transportation \\
\hline 17 & SS & many parking lots \\
\hline 20 & IE & thermal comfort \\
\hline 23 & MR & $\begin{array}{l}\text { successful waste } \\
\text { management }\end{array}$ \\
\hline 24 & IE & better views of patient rooms \\
\hline 27 & EA & $\begin{array}{l}\text { utilization of trigeneration } \\
\text { system }\end{array}$ \\
\hline 32 & WE & savings in water usage \\
\hline 33 & EA & savings in energy cost \\
\hline
\end{tabular}

Successful waste management and utilization of a trigeneration system named advantages were not included in the process, as their median value obtained in the Delphi technique are less than 6 . Thus, there are a total of 7 seven advantages evaluated in AHP to find their relative importance. Same fifteen experts were requested to list these 7 seven advantages in terms of their importance. The experts scaling of these advantages and the consistency ratio of each evaluation is presented in Table 6.

\subsection{Discussion of results}

As seen in Table 6, the consistency ratio of all experts is less than $10 \%$ meaning the inconsistency of the answers of each expert is within the acceptable range. The results indicate that easy transportation, existing many parking lots, and reduced energy/water/gas cost are the most valuable advantages of working at a LEEDcertified hospital in Turkey.

Fig. 3 below indicates Table 6 results from another perspective. In this figure, it represents how many times the related advantage was scaled as the most valuable. As shown in the figure, easy transportation was scaled as the most valuable advantage. Additionally, both existing many parking lots and thermal comfort was scaled as the most valuable advantage by two other experts.

Table 6. Scaling of advantages (all values are in percentages)

\begin{tabular}{lccccccccccc}
\hline $\begin{array}{l}\text { Advantage Name / } \\
\text { Expert No }\end{array}$ & 1 & 2 & 3 & 4 & 5 & 6 & 7 & 8 & 9 & 10 & Total \\
\hline $\begin{array}{l}\text { Reduced } \\
\text { energy/water/gas cost }\end{array}$ & 20 & 28 & 13 & 14 & 13 & 16 & 20 & 14 & 9 & 15 & 160 \\
Easy transportation & 32 & 22 & 26 & 18 & 18 & 15 & 32 & 21 & 14 & 13 & 211 \\
Many parking lots & 9 & 12 & 27 & 18 & 15 & 31 & 9 & 16 & 11 & 13 & 163 \\
Thermal comfort & 15 & 15 & 8 & 21 & 26 & 10 & 15 & 16 & 12 & 15 & 151 \\
Better views of patient & 9 & 7 & 10 & 8 & 9 & 10 & 9 & 9 & 11 & 10 & 94 \\
rooms & 6 & 6 & 8 & 12 & 9 & 9 & 6 & 14 & 27 & 13 & 111 \\
Savings in water usage & 9 & 9 & 7 & 9 & 9 & 9 & 9 & 12 & 17 & 21 & 111 \\
Savings in energy cost & 9,2 & 9,9 & 9,0 & 6,5 & 7,5 & 6,6 & 9,2 & 5,5 & 6,4 & 8,4 & \\
Consistency Ratio & & & & & & & & & & \\
\hline
\end{tabular}




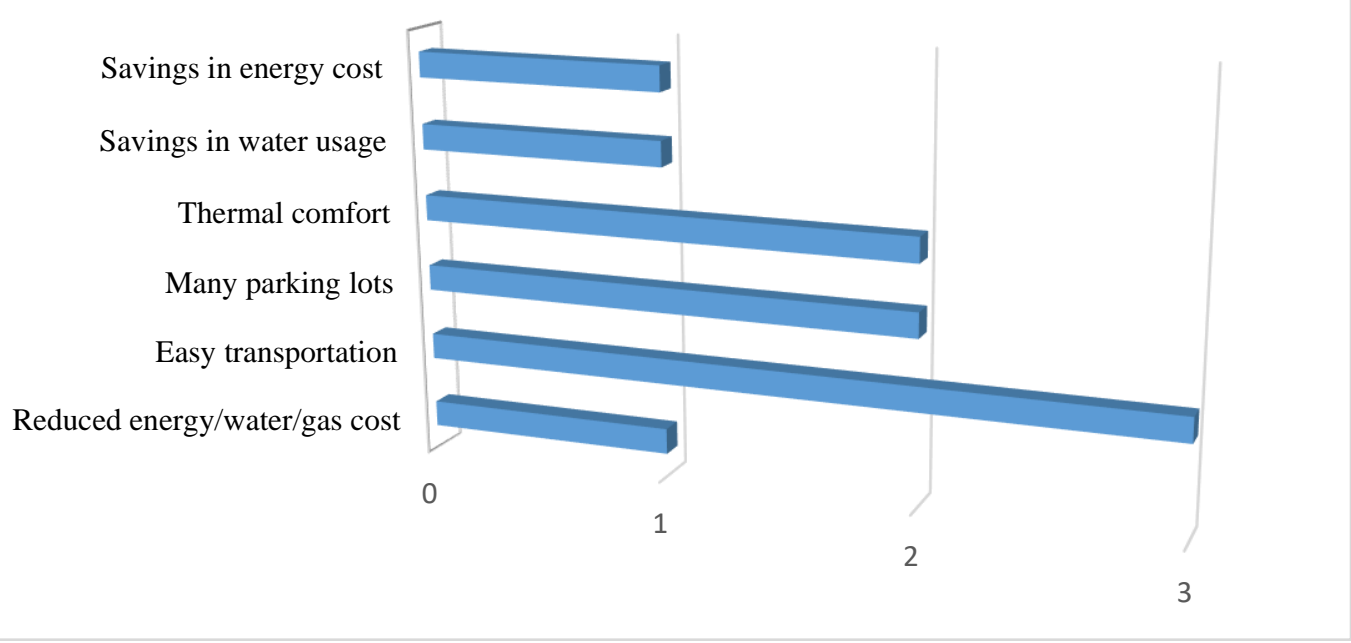

Fig. 3. Number of advantages from LEED criteria that are scaled as the most valuable

\section{Conclusion}

In conclusion, LEED certification criteria for hospital buildings have been evaluated in this article from end user's perspective. Questionnaires have been provided to experts from the industry who have working experience for both LEED and non-LEED certified hospitals. First of all, the Delphi technique was utilized to acquire the most valuable advantages of working at a LEEDcertified hospital. The obtained long list was shortened with their relevance to LEED certification criteria. The shortlist was again relisted by experts' opinion for their relative importance to each other with the help of the AHP technique due to shortcomings of the Delphi technique to provide the mentioned priority. In the end, the initial hypothesis of the authors was confirmed such that easiness and comfort values of LEED criteria is the most valuable LEED certification criteria from the end user's perspective also. In other words; savings in cost, thermal comfort, easy transportation and existing many parking lots are the most valuable advantages according to end user's opinion which is also LEED certification criteria that are related to easiness and comfort. For future works related to this topic, a focus group of experts' number can be increased, and the same procedure explained in this article can be repeated. This study can also be repeated for buildings in sectors other than healthcare to find out about the preferences of end-users in relation to LEED certification criteria.

\section{References}

[1] Enache-Pommer E, Horman MJ, Messner JI, Riley D. A Unified process approach to healthcare project delivery: synergies between greening strategies, lean principles and BIM. Construction Research Congress 2010.

[2] USGBC (2018) United States Green Building Council. Retrieved from https://www.usgbc.org

[3] Buffoli M, Capolongo S, Noia MD, Gherardi G, Gola M. Healthcare sustainability evaluation systems. In: Capolongo, S., Bottero, M., Buffoli, M., Lettieri, E. (ed), Improving Sustainability During Hospital Design and Operation: A Multidisciplinary Evaluation Tool, Green Energy and Technology, 2015, pp 23-29.

[4] Wittmann M. Sustainable healthcare design. In: McCullough, C.S. (ed), Evidence-Based Design for Healthcare Facilities, Sigma Theta Tau International, 2010, pp 147-186.

[5] Phelps A, Horman M, Barr M, Brower J, Riley D, Vagenas J, Pearce A. Greening healthcare facilities roundtable: report of the roundtable event. Research Report, Pennsylvania State University, 2006.

[6] Xuan X (2016). Study of indoor environmental quality and occupant overall comfort and productivity in LEED and non-LEED certified healthcare settings. Indoor and Built Environment, 27(4), 544-560. 
[7] Kim SK, Hwang Y, Lee YS, Corser W (2015). Occupant comfort and satisfaction in green healthcare environments: a survey study focusing on healthcare staff. Journal of Sustainable Development, 8(1), 156-173.

[8] Huang Y. Impact of Green Building Design on Healthcare Occupants with a Focus on Healthcare Staff. MSc Thesis, Michigan State University, 2011.

[9] Harris DD (2014). Return on investment of a LEED platinum hospital: the influence of healthcare facility environments on healthcare employees and organizational effectiveness. Journal of Hospital Administration, 3(6), 37-55.

[10] Sadatsafavi H, Walewski J, Taborn II M (2015). Patients' experiences with hospital carecomparison of a sample of green hospitals and nongreen hospitals. Journal of Green Building, 10(1), 169-185.

[11] Ulusoy E. Comparison of LEED TO Non LEED Certified Hospitals with regards to Patient Perspective and Financial Indicators. MSc Thesis, Texas A\&M University, 2012.

[12] Sahin EA (2001). Eğitim araştırmalarında Delphi tekniği ve kullanımı. Hacettepe Üniversitesi Eğitim Fakültesi Dergisi, 20, 215-220.

[13] Saaty TL. The Analytic Hierarchy Process. McGraw-Hill, New York, 1980. 